\title{
A Reply to the Julius Blumfeld Review of Escape from Leviathan
}

\section{J. C. Lester}

The Julius Blumfeld review (the review) of Escape from Leviathan (EfL) includes various kind words and especially welcome criticisms. ${ }^{1}$ This reply attempts to respond to the criticisms as best as it can. There have been further replies to criticisms, additional articles, and even books clarifying and developing this overall philosophical theory of libertarianism in the time that has elapsed since the first version of this reply. ${ }^{2}$ Consequently, it is now possible to revise it to make it somewhat clearer.

Yes, libertarian thinkers cannot "prove or justify libertarianism". ${ }^{3}$ Justificationists will reject the critical-rationalist approach in EfL. And this means that it faces an extra but, it seems, necessary hurdle. However, it is worth adding that justificationists often do something valuable nevertheless, namely explaining libertarianism. For so-called justifications (foundations, supports, groundings, etc.) are often really explanations of how libertarianism is supposed to work or what sorts of things are desirable about it. But these explanations are themselves, perforce, ultimately conjectural, highly limited, and rarely as clear as they might be if their proponents understood this. So, although they cannot achieve their ostensible purpose, we ought not to dismiss everything written in the name of being a 'justification' as thereby without any value.

The review suggests that EfL has left "certain questions tantalisingly unanswered". A closer reading of the book might reveal some answers to these questions after all. But no doubt those answers could have been stated more clearly, which will be attempted here. The review asks first, "Why are liberty, welfare and anarchy compatible?" There are two general answers, which are each composed of a potentially unlimited number of specific answers. First, it is partly causal, contingent, and empirical. For instance, it is a contingent fact about the free market as an aspect of liberty that it increases wantsatisfaction welfare. People are individually aiming to maximise their want-satisfaction. And free markets, along with other voluntary interactions, are usually the route they take with manifest success. We can easily imagine constant market disasters that would do no such thing. Second, it is also partly conceptual, necessary, and philosophical. For instance, anarchy is not being ruled and that just is an extreme form of an aspect of liberty. While interpersonal liberty, as not being initiatedly imposed on, is ipso facto desirable in itself and thus far welfare-enhancing.

However, there are arguments in EfL explaining how the conceptual connections are not tendentious tautological definitions. For the various theories (of aprioristic-instrumental rationality, noinitiated-imposition liberty, want-satisfaction welfare, and private-property anarchy) withstand both critical scrutiny and competing theories as being the accounts that explain the Classical Liberal Compatibility Thesis ${ }^{4}$ (the Compatibility Thesis) that these things do not significantly clash in practice. There are certainly some conceptual connections between the "definitions" (really, theories) of "liberty and welfare" (also anarchy and rationality) but not enough, it is argued in EfL, to say that they are really "similar" theories, as the review suspects, that approach being tautologically connected. For EfL allows the clear possibility that its several conceptions could diverge in a multiplicity of ways, but then it brings in evidence and arguments to explain that they do not do so as a matter of reality. Consequently, it does not seem true of liberty and welfare, as specifically cited, that "at some deeper level they are the same thing or ... both manifestations of some deeper underlying principle" (unless, perhaps, that "principle" is classical liberalism itself). It ought to be noted that the conception of 'welfare' used in EfL is also used in welfare economics and preference utilitarianism. Hence, it is hardly an eccentric conception or one that is clearly engineered in order to fit the theory of liberty. In fact, welfare-economics and preference-utilitarian texts typically argue for state intervention in very many areas. What of the

\footnotetext{
${ }^{1}$ Blumfeld, Julius. 2005. “An important advance in libertarian theory” (Amazon: https://www.amazon.co.uk/gp/customerreviews/RF779VKZL 7K7R/ref=cm cr_dp_d_rvw_ttl?ie=UTF8\&ASIN=0333777565).

${ }^{2}$ For a short and clear introduction to this philosophical theory of libertarianism see Lester, J. C. 2022. "Eleutheric Conjectural Libertarianism: a Concise Philosophical Explanation" (PhilPapers: https://philpapers.org/rec/INDNLA). ${ }^{3}$ Epistemological 'supporting justifications' of observations, theses, and theories face a trilemma: they are all based on unsupported assumptions, and any attempt to support those assumptions entails infinite regress, or dogmatic assertion, or circularity (none of which can offer support).

${ }^{4}$ This being an extreme and more precise version of the general classical-liberal insight that private property strongly tends to promote the personal liberty and prosperity of everyone.
} 
converse view, that the theory of liberty is designed to fit the theory of welfare? First, the theory of 'liberty' is explained and defended as entailed by libertarianism without any reference to welfare. Second, as already noted, it is clear that even such liberty logically could clash with welfare (it is likely that statists would claim that this clash is real, and some of them might even happily embrace the theory of liberty).

The review also alleges that $E f L$ "provides only limited guidance as to how we are to derive rules and laws that will maximise liberty". However, EfL first explains and defends an abstract theory of interpersonal liberty-in-itself. Then it explicitly explains how self-ownership, physical property, intellectual property, and contracts are derived from maximising liberty. It also deduces-albeit in a scattered manner as various problems arise - an individualistic liberty-maximisation theory for dealing with clashes, defences, and rectifications. This is all ultimately a philosophical explanation — but with various empirical assumptions - though it appears to offer what are sufficient to be the review's requested "concrete criteria" in terms of "rules and laws". Where there are additional difficult and novel cases, then we would sometimes have to resort to the original abstract theory of liberty-in-itself or the individualistic maximisation principle.

For instance, David Friedman correctly cites various cases where absolute property rights do not work. One case is of any trivial light-source generated on your property not being allowed to cross onto my property without my permission. EfL's solution is that the person 'suffering' the light 'trespass' is usually a lesser imposition (in fact, usually too trivial for compensation; especially as it is likely a reciprocal 'trespass') than someone's having to go without lights or needing to have perfectly lightproof curtains that must be closed at all times that any light is on. Given such clashes of liberty, we must prefer the lesser imposition as maximising liberty (and, as Friedman does realise, maximising preference-utility). But with substantial one-sided clashes compensation, or even proscription, may be due. Having such an abstract theory of liberty-in-itself and how to maximise it seems to be the opposite of being a "pragmatist", as the review alleges. It appears that only by applying these theories can we ultimately "derive libertarian laws and rules". Economic analysis might assist in this, but — contra David Friedman's view - economics cannot in itself be "the best way to derive libertarian laws and rules". Economics can explain where maximum utility or efficiency lies; but only EfL's theory of liberty can explain how this is where maximum liberty is also to be found.

It is probably an understatement that EfL's theory of libertarian interpersonal liberty "does not always fit comfortably with the meaning that most libertarians would attach to it". It is quite different from many other definitions or theories: for instance, by rejecting 'coercion', the 'harm principle', and 'aggression' as being at all relevant; and rejecting self-ownership and private property as central, rather than derived from applying abstract liberty (and to be set aside when they clash with it). Most of the other libertarian conceptions of 'liberty' are at best vague and usually tacit. EfL is trying to capture the theory of liberty that they presuppose, or logically entail. EfL originally explains abstract interpersonal liberty as being "the absence of initiated imposed costs (on persons by other persons)" and then immediately abbreviates this, for convenience, to "the absence of imposed costs". It now appears that it is slightly clearer to write of 'the absence of initiated imposed costs' (or simply 'the absence of initiated impositions').

However, that formulation is the abstract theory of interpersonal liberty-in-itself in a prepropertarian world. Once libertarian property has been derived (as acquired and held in a way compatible with the theory of abstract liberty and its rules for maximisation), then it would usually be clearer in everyday life to speak of any 'initiated impositions' as referring to any infractions of libertarian property (including property in one's own body). Thus, the initiatedly-imposed damage to the reviewer's car bumper is indeed a type of "loss of liberty" in the defended sense. Admittedly, this is an unusual way to describe it. Perhaps it sounds less odd to call this 'infringing an aspect of liberty'. Complete libertarianism does imply having all laws ultimately derivable from applying liberty. This might sound extreme, even fanatical, but that is what full libertarianism entails. Without it we would have undecidable or incomplete laws from a libertarian viewpoint, and possibly additional principles that are sometimes inconsistent with liberty.

What of the "scope of the conjecture", i.e., the Compatibility Thesis? It is stated in EfL that it is supposed to be a practical conjecture about the real world. Liberty and welfare, most obviously, have a strong tendency to go hand in hand. We can see that they will occasionally conflict - in particular at the micro and personal level - but this will not be often enough for us to be able to alter the overall rules 
to increase liberty or welfare (because of the local knowledge problem, moral hazards, and unintended consequences generally). Is the review's postulated "small but identifiable group of people [who] would be indisputably worse off in a world of maximum liberty" a refutation? EfL rules out mere logical possibilities as being refutations. How can liberty and welfare plausibly clash in reality even for a "small but identifiable group of people"? We can relevantly discuss any putative real cases (although this would probably be to leave the realm of philosophy).

The review's final question is, "Does welfare mean welfare for literally everybody or just most people?" The thesis is not that everyone will always have more welfare if liberty is maximised. The main thrust of the Compatibility Thesis is that there are no systematic or significant practical clashes between maximising liberty and maximising welfare such that we have to choose between them (the rationality and anarchy theories are really there to clarify and complement this). For instance, if the state really were able to improve welfare (via its legislation, education, healthcare, etc.) compared to the market, charity, and other consensual arrangements, then we would have just such a clear practical clash. But, as libertarians suppose, we do not. Of course, non-libertarians disagree. For them the Compatibility Thesis will be completely implausible on its face on that account alone. The purpose of this philosophical theory of libertarianism is primarily to clarify philosophical confusion and solve philosophical problems with this ideology. It is not, on its own, intended to persuade people of the merits of libertarianism. By putting a theory of liberty at its centre (instead of a theory of property), being conjecturalist (instead of justificationist), and making moral defences separate (instead of conflated with all the other issues) it is a paradigm shift away from the conception of classical liberalism and libertarianism that has been dominant since John Locke's Second Treatise.

(January 2006; revised January 2022.) 